\title{
Research on Practice Teaching of Hydrology and Water Resources Specialty*
}

\author{
Qianqian $\mathrm{Wu}^{1}$ \\ Shandong University of \\ Science and Technology \\ Dongsheng Wang ${ }^{4}$ \\ Ocean University of China
}

\author{
Jiaguo Ren ${ }^{2}$ \\ Shandong University of \\ Science and Technology \\ Puchuang $\mathrm{Gao}^{5}$ \\ Shandong University of \\ Science and Technology
}

\author{
Zuozhen $\operatorname{Han}^{3}$ \\ Shandong University of \\ Science and Technology \\ Qiang $\mathrm{Wu}^{6}$ \\ Shandong University of \\ Science and Technology
}

\begin{abstract}
Practical teaching is an important part of personnel training in Colleges and Universities. It plays an important role in improving the quality of personnel training, so practical teaching construction must be strengthened. Taking the undergraduate teaching of hydrology and water resources as an example, this paper puts forward that the practical teaching system can be composed of course assignment, practice, social practice, scientific research cases and engineering practice ability training. The role of typical case teaching method in teaching is emphatically analyzed, and the ability of independent scientific research projects is proposed to improve undergraduate students' practical skills and innovation ability.
\end{abstract}

\section{Keywords}

Hydrology and Water Resources • Practical Teaching • Curriculum System

\footnotetext{
*This work is funded by Scientific Research Foundation of Shandong University of Science and Technology for Recruited Talents (No.2016RCJJ009), Stars plan Project of Shandong University of Science and Technology (QX2018Z02),Shandong Provincial Natural Science Foundation (ZR2017MD009) and National Natural Science Foundation of China (No. 41202165, No. 41102149).

${ }^{1}$ College of Earth Science and Engineering, Shandong University of Science and Technology, Qingdao 266590, China. Email: wqq912@126.com

${ }^{2}$ Correspondence to: Jiaguo Ren, College of Earth Science and Engineering, Shandong University of Science and Technology, Qingdao 266590, China. Email: renjiaguo2008@126.com

${ }^{3}$ College of Earth Science and Engineering, Shandong University of Science and Technology, Qingdao 266590, China. Email: hanzz@163.com

${ }^{4}$ Ocean University of China, Qingdao 266100, China. Email: wds@ ouc-edu.com

${ }^{5}$ College of Earth Science and Engineering, Shandong University of Science and Technology, Qingdao 266590, China. Email: 1351576309@qq.com

${ }^{6}$ College of Earth Science and Engineering, Shandong University of Science and Technology, Qingdao 266590, China. Email: 2418659510@qq.com
}

Citation: Wu, Q. Q., Ren, J. G., Han, Z. Z., Wang, D. S., Gao, P. C., Wu, Q. (2018). Research on Practice Teaching of Hydrology and Water Resources Specialty. Educational Sciences: Theory \& Practice, 18(5), 2332-2337. http://dx.doi.org/10.12738/estp.2018.5.131 
With the expansion of the scale of higher education, the quality of College graduates' training has gradually emerged, and there is a common phenomenon that the basic knowledge is solid, but the ability of practice and innovation is weak. How to ensure that college graduates meet the needs of social and economic development in the new situation has become a problem of higher education (Liu, 2015).

In the 18th century, Scotland began to establish a higher education university which combines teaching with research; at the end of the 19th century, Germany has initially formed a higher education system model characterized by professional research; Harvard University in the United States has been committed to discovering new knowledge in various disciplines, retaining, interpreting, reinterpreting current knowledge and helping students master methods, knowledge, skills and inquiries, so that students will continue to pursue knowledge throughout their lives and lead social progress (Zhang et al., 2015; Jiang \& Yang, 2013). Nowadays, research and education universities still have to comply with the requirements of the times of "taking the road of practical teaching and implementing quality-oriented education in an all-round way", constantly improve their integrative quality, combine practice with teaching organically, and take teaching as the centre to improve teaching quality (Wang, 2014).

\section{The construction of hydrology and water resources specialty}

The specialty of hydrology and water resources engineering in our University actively responds to the requirement of national construction of first-class disciplines, formulates the personnel training scheme to meet the needs of the development of disciplines under the new situation, enriches the contents of courses and textbooks, fully carries out experimental practice, promotes the level of team teaching and research, and forms the model of the construction of hydrology specialty. as shown in Figure 1

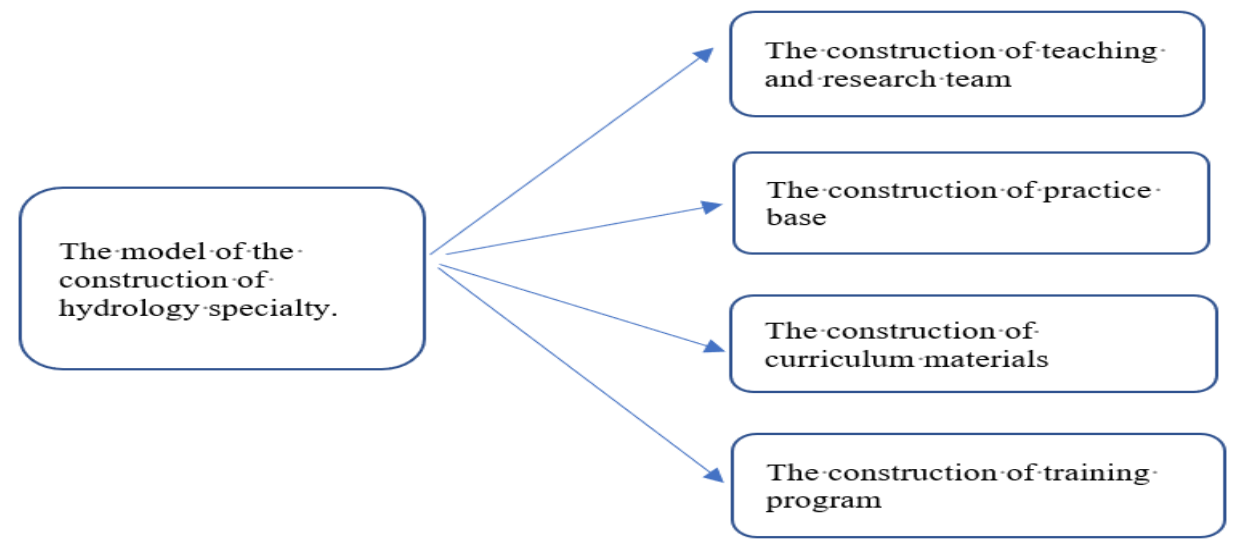

Figure 1. The construction of hydrology and water resources specialty. 
Wu, Ren, Han, Wang, Gao, Wu / Research on Practice Teaching of Hydrology and Water Resources Specialty

We should set professional training objectives and curriculum syllabus around the hydrology and water resources specialty and construct practical teaching system of the course from the three aspects of case analysis, homework and teaching practice in theoretical teaching.

\section{Practice teaching construction}

Practice teaching system runs through the teaching link all the time. Each stage is composed of typical training link and corresponding theoretical knowledge, which are complementary and self-contained (Du, 2014; Guo, 2018; Guo et al., 2015). We should think of the diversified and multi-level practical teaching system with basic quality and comprehensive professional ability as the main line and set up a cultivation model which contains practical teaching, scientific research and production so as to improve their production practice and design ability, such as the following.

\section{Establish professional teaching practice base}

We should strengthen the cooperation between schools, enterprises, colleges and universities as well as between schools and scientific research institutes, increase opportunities for teaching practice, improve students' practical skills, and form a good situation of "interaction, mutual research, mutual teaching and mutual learning" with cooperative units. Establish a solid practice teaching base inside and outside the school, increase the investment of manpower and material resources in the construction of the base, when necessary, choose doublequalified teachers who understand the theory and possess the strong ability of practice to enrich the practice base inside the school (Jin, 2015; Zhang et al., 2015).

Establish a solid practice teaching base inside and outside the school, set up a Qingdao Hydrology Bureau, Shandong Province Bureau of Geology and Mineral Resources, Geological Survey Institute and other practice teaching bases, so that students really put the knowledge learned into practice, truly understand the use of professional courses, improve interest in learning.

\section{Implement typical case teaching}

Changing the traditional teaching method of "imparting" in the past, the author applies various flexible and vivid teaching methods such as heuristic method and discussion method to classroom teaching, enlightening students and arousing their creativity.

Case teaching of scientific research. Choose scientific research topics with appropriate degree of difficulty, closely related to teaching content and professional characteristics in classroom teaching. It makes the students study and explore the knowledge of scientific problems in the excavation and thinking of specific scientific research cases, raises the perceptual knowledge to the level of rational knowledge, and makes the students try to discover knowledge from the process of "accepting knowledge" to the process of "discovering knowledge". 
Writing course papers. Students will be assigned frontier hot topics in the field. Students will write small papers by reading materials and consulting literature. Teachers should lead the whole class discussion or the discussion of student lectures in the classroom teaching. the students should analyse, interpret, discuss the problems involved in each topic with the prompt and guidance of teachers. Encourage students to fully express themselves in analyzing problems, enhance their self-confidence, and give full play to their creative thinking.

Design comprehensive experiments. The theoretical teaching should be transformed into teaching experiment in time. On the basis of students participating in scientific research projects, a design comprehensive experiment is set up. The experiment project is handed over to the students. In order to cultivate students' comprehensive ability and skills, students should design the experiment scheme independently by consulting the relevant materials in the short term, and then form the feasible experiment scheme under the guidance of the teacher, and complete the experiment task independently.

Develop research-oriented Teaching. We should integrate the latest achievements of scientific research into teaching, update teaching materials and contents in time, invite experts from relevant fields to give special lectures, introduce the contents of scientific research projects undertaken by teachers into teaching, use the papers published by teachers as extracurricular reading materials, enrich classroom teaching content and improve curriculum quality (Zhang et al., 2015).

\section{Cultivate engineering practice ability}

According to the needs of students at different levels under the credit system, the major of hydrology and water resources should change their concepts, improve their understanding, optimize their models, improve their quality and efficiency, redesign training plans, construct training system of engineering practical ability, and strengthen students' practice to cultivate students' innovative ability and engineering practical ability, as shown in Figure 2.

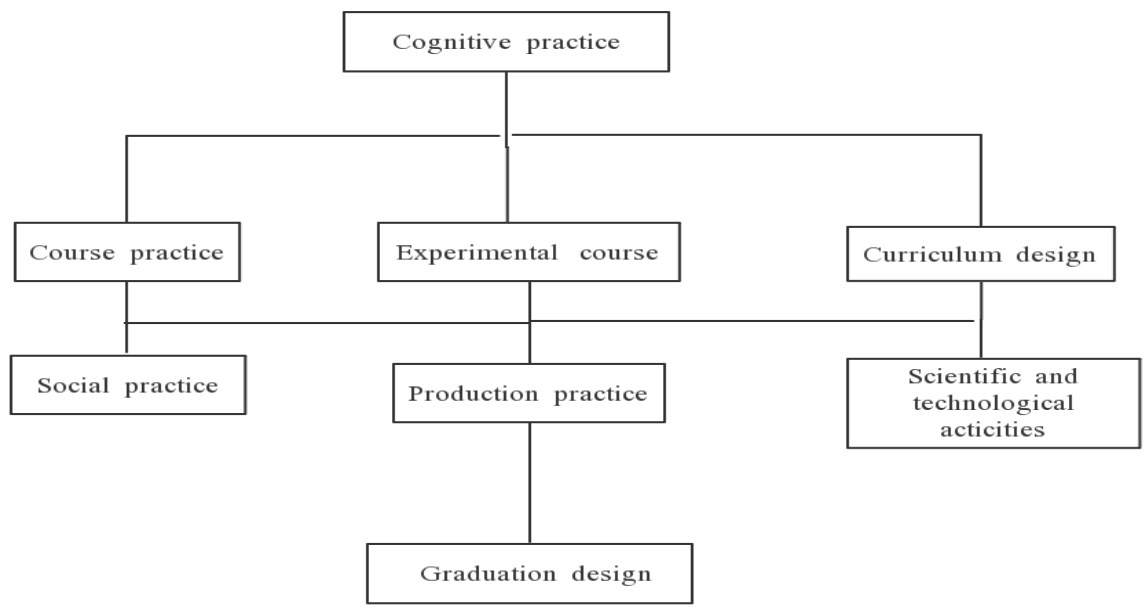

Figure 2. Training of engineering practice ability. 
Wu, Ren, Han, Wang, Gao, Wu / Research on Practice Teaching of Hydrology and Water Resources Specialty

Engineering practice ability cultivation is divided into four levels. The first level, we should combine inschool laboratory visits with out-of-school project visits, so that students have a basic understanding of the specialty. The second level, we should combine in-class and out-of-class theory and practice through laboratory courses, professional course practice and curriculum design. The third level, we should strengthen students' preliminary application ability of professional knowledge through production practice, social practice and extracurricular scientific and technological activities, so that students' basic theory and engineering practice can be further integrated. The fourth level, students' ability to solve practical problems systematically can be cultivated through the graduation design and the solution of engineering practical problems. Four levels of training in school and out of school combined with theory and practice to strengthen students' innovative ability and engineering practice ability through four levels of training in school and out of school combined with theory and practice.

\section{The epilogue}

At present, the practice teaching system of hydrology and water resources engineering specialty has been established, and has a more mature practice base. In order to make it develop steadily, in view of the problems existing in the process of practice teaching, it is not only necessary to reform the basic knowledge, basic working methods and skills training, but also to explore the optimization ways of practice teaching system, so as to cultivate applied and professional talents adapted to the new era and new environment.

Through several years of exploration and improvement, the teaching practice system of hydrology and water resources engineering has been preliminarily formed. Students ' practice and working ability have also been steadily improved. Professional practice teaching has also made some achievements. However, this is a longterm and arduous task, which requires the efforts of all professional teachers and different departments of the school to cooperate, communicate and communicate, so that the practical teaching of hydrology and water resources engineering can achieve the best results.

We should improve students' interest in learning, change passive learning into active exploratory learning, promote students' creative thinking and innovative ability in teaching, ensure high-quality personnel training through high-quality curriculum construction to improve the teaching level of courses, so as to cultivate students' comprehensive ability and scientific research quality, and cultivate the urgent need of society applied talents.

\section{References}

$\mathrm{Du}, \mathrm{H}$. (2016). Research on training mode of hydrology and water resources engineering talents in ethnic universities based on employment orientation. Science and Technology Innovation Herald, (27), 123-125.

Guo, J. L., Peng, T., \& Liu, J. (2015). Research on engineering consciousness and practical ability training of students majoring in hydrology and water resources engineering. Education Modernization, (14), 65-68. 
Wu, Ren, Han, Wang, Gao, Wu / Research on Practice Teaching of Hydrology and Water Resources Specialty

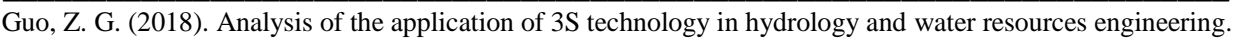
Modern Property Management, (05), 52-53.

Jiang, J. F., \& Yang, Z. G. (2013). Preliminary study on talent training mode of hydrology and water resources engineering in urban construction colleges. Guangzhou Chemical Industry, (10), 225-227.

Jin, X. (2015). Development direction of Guangxi hydrology and water resources engineering undergraduate specialty. The Guide of Science \& Education, (12), 30-32.

Liu, X. (2015). Research on personnel training and guarantee system of hydrology and water resources engineering in the new situation. South China Agriculture, 9(9), 142-144.

Wang, F. Q. (2014). Research on personnel training and guarantee system of hydrology and water resources engineering in the new situation. Science and Technology Innovation Herald, (24), 199-200. http://dx.chinadoi.cn/10.3969/j.issn.1674-098X.2014.24.137

Zhang, Y. B., Zhang, Z. X., Yang, J. Y., Zhao, Z. L., \& Zhao, X. H. (2015). Curriculum system construction of hydrology and water resources engineering. Science and Technology Innovation Herald, (18), 133-134, 184

Zhang, Y. B., Zhang, Z. X., Yang, J. Y., Zhao, Z. L., \& Zhao, X. H. (2015). Discussion on practice teaching reform of hydrology and Water Resources Engineering Specialty. Ground Water, (05), 133-134, 141.

Zhang, Z. F., Zhang, Z. X., Yang, J. Y., Zhao, Z. H., \& Zhao, X. H. (2015). Research on talent training mode of combination of production, teaching and research in hydrology and water resources engineering. Education Teaching Forum, (25), 67-68. 